\title{
Sustained Remission: An Unmet Need in Patients with Giant-cell Arteritis
}
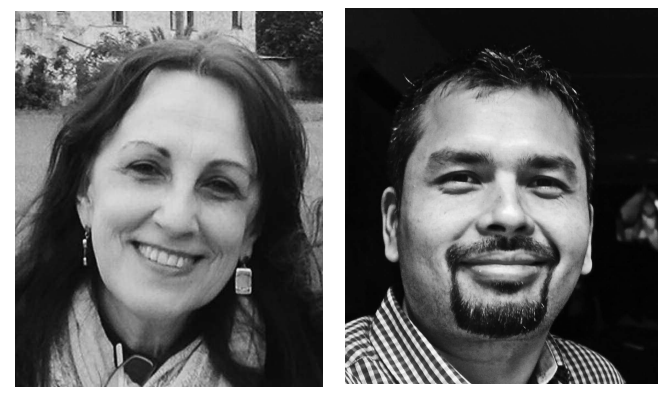

Giant-cell arteritis (GCA) has been considered a paradigm of glucocorticoid-responsive disease because the majority of patients experience substantial relief of their symptoms with high-dose glucocorticoids (GC). However, GC may not completely suppress crucial immunopathogenic pathways, eventually leading to disease recurrence ${ }^{1,2}$. GCA has been largely recognized as a relapsing disease. However, many unanswered questions about relapses have been only infrequently addressed in the literature and await better characterization.

To begin with, there is no consensus definition of relapse. In the majority of randomized controlled trials of GC-sparing agents, relapse, which is the essence of the primary endpoint, is defined by reappearance of specified GCA-related symptoms ${ }^{3,4,5,6}$. In some, but not in all of them, a concomitant increase in serum acute-phase reactants [usually erythrocyte sedimentation rate (ESR) or C-reactive protein (CRP)] is required. However, reappearance of GCA-related clinical features has not always been mandatory and, in other studies, although establishing a precise threshold may be difficult and somehow arbitrary, isolated increases in acutephase reactants are also considered disease flares ${ }^{7,8}$. In other reports, relapses rely on the judgment of treating physicians, with no specific definition ${ }^{9}$.

Several additional questions are highly relevant to clinicians managing patients with GCA. What are the expected frequency and clinical manifestations of relapse? Who are the patients at risk? When are relapses more likely to occur? What is the effect of relapse on disease or treatment-associated morbidity?

In this issue of The Journal, Kermani, et al contribute some answers to these important questions by investigating the frequency and clinical features associated with relapse in a prospective, longitudinal, multicenter study including 128 patients with $\mathrm{GCA}^{9}$. Relapses, defined by the treating physician, occurred in 34\% of patients during a median followup of 21.4 months $( \pm 13.9$ ). This percentage is somehow lower than that reported in previous studies. The highest relapse rates $(76 \%-84.2 \%)$ have been described in clinical trials of adjuvant therapies where aggressive GC-tapering schedules designed to evidence the potential GC-sparing efficacy of the investigational product have been applied $3,4,5,6,8$. Outside clinical trials, reported frequencies in prospective observational studies range from $36 \%$ to $64 \%^{10,11,12,13}$. The lower frequency of relapses found in the present study may be related to the fact that followup was shorter than in other existing studies and that patients were not enrolled from the very beginning: at the time of recruitment, 39\% had already experienced a flare. In keeping with previous studies, the more frequent symptoms at the time of relapse were headache and polymyalgia rheumatica $^{11,13}$. Interestingly, $21 \%$ of flares were not associated with elevation of ESR or CRP. Of note, visual symptoms as well as symptoms of vascular insufficiency (jaw or limb claudication) may also occur during relapses but are less frequent (7-14\%). Fortunately, irreversible sight loss is unusual during controlled flares $\mathrm{s}^{9,11,12,13,14}$

Another relevant aspect is the prednisone dose below which a disease flare may be expected. Kermani, et al remark that, in their cohort, patients with GCA rarely relapsed while receiving more than $20 \mathrm{mg}$ of daily prednisone. The majority of relapses occurred in patients receiving $<10 \mathrm{mg}$ prednisone/day. No patients in the series described by Alba, et al flared while receiving more than $25 \mathrm{mg}$ a day ${ }^{13}$. Taken together, these results indicate that in patients who, after achieving remission, develop symptoms while receiving above $20-25 \mathrm{mg} /$ day, confounding factors or an alternative diagnosis may need to be considered, including other systemic vasculitis mimicking GCA.

Relapses may occur at any time, but in accordance with previous reports, flares mainly occur during the first 2 years after initiation of treatment and subsequently become less frequent. Moreover, over the years, relapses occur at lower GC doses and are accompanied by less prominent laboratory abnormalities ${ }^{13}$. These findings may suggest that disease activity tends to decrease over time after longterm followup.

Because most patients were not enrolled at the time of diagnosis, Kermani, et al did not analyze the role of

See Relapse in GCA, page 1213

Personal non-commercial use only. The Journal of Rheumatology Copyright @ 2015 . All rights reserved. 
presenting clinical findings or blood tests as predictors of relapse. No clear or strong predictors of relapse have been, in fact, identified although some studies have shown that findings related to the intensity of acute-phase response (i.e., anemia, systemic complaints, highly elevated ESR), when assessed before starting treatment, are associated with higher relapse risk ${ }^{11,13,15,16}$.

An important question about relapse, which has not been comprehensively addressed and needs to be further investigated, is whether repeated flares of disease activity are associated with disease or treatment-associated morbidity. Various studies point out that disease-related irreversible ischemic complications are infrequent during controlled relapses ${ }^{9,13,14}$, but it has not been established whether repeated relapses may favor vascular stenoses or dilatation. This is an important and still unanswered question. Preliminary data do not support that relapsing disease increases the risk of aortic aneurysm ${ }^{17,18}$

Another relevant issue is whether relapsing disease leads to higher cumulated GC doses and ensuing side effects. This was indeed the case in a study in which patients with relapsing disease had significantly higher cumulated prednisone doses and higher frequency of osteoporosis ${ }^{13}$. Associations between higher cumulated GC doses and the development of GC-related adverse events have been demonstrated in additional studies ${ }^{12,19}$.

Therefore, as Kermani, et al conclude, treatment remains unsatisfactory for patients with GCA, and achieving sustained remission is an important unmet need.

\section{MARIA C. CID, MD;}

MARCO A. ALBA, MD;

Vasculitis Research Unit,

Department of Autoimmune Diseases,

Hospital Clínic, University of Barcelona,

Institut d'Investigacions Biomèdiques August Pi i Sunyer (IDIBAPS),

Barcelona, Spain.

Supported by Ministerio de Economía y Competitividad [SAF 11(30073)], Consejo Nacional de Ciencia y Tecnología, Mexico, and Agencia de Gestió d'Ajuts Universitaris i de Recerca (Generalitat de Catalunya). Address correspondence to Dr. M.C. Cid, Department of Autoimmune Diseases, Hospital Clínic, Villarroel 170, 08036-Barcelona, Spain. E-mail: mccid@clinic.ub.es

\section{REFERENCES}

1. Weyand CM, Goronzy JJ. Immune mechanisms in medium and large-vessel vasculitis. Nat Rev Rheumatol 2013;9:731-40.

2. Visvanathan S, Rahman MU, Hoffman GS, Xu S, García-Martínez A, Segarra M, et al. Tissue and serum markers of inflammation during the follow-up of patients with giant-cell arteritis - a prospective longitudinal study. Rheumatology 2011;50:2061-70.

3. Jover JA, Hernández-García C, Morado IC, Vargas E, Bañares A, Fernández-Gutiérrez B. Combined treatment of giant-cell arteritis with methotrexate and prednisone. A randomized, double-blind, placebo-controlled trial. Ann Intern Med 2001;134:106-14.

4. Hoffman GS, Cid MC, Hellmann DB, Guillevin L, Stone JH, Schousboe J, et al. A multicenter, randomized, double-blind, placebo-controlled trial of adjuvant methotrexate treatment for giant cell arteritis. Arthritis Rheum 2002;46:1309-18.

5. Martinez-Taboada VM, Rodriguez-Valverde V, Carreno L, Lopez-Longo J, Figueroa M, Belzunegui J, et al. A double-blind placebo controlled trial of etanercept in patients with giant cell arteritis and corticosteroid side effects. Ann Rheum Dis 2008;67:625-30

6. Hoffman GS, Cid MC, Rendt-Zagar KE, Merkel PA, Weyand CM, Stone $\mathrm{JH}$, et al. Infliximab for maintenance of glucocorticosteroid-induced remission of giant cell arteritis: a randomized trial. Ann Intern Med 2007;146:621-30.

7. Mazlumzadeh M, Hunder GG, Easley KA, Calamia KT, Matteson EL, Griffing WL, et al. Treatment of giant cell arteritis using induction therapy with high-dose glucocorticoids: a double-blind, placebo-controlled, randomized prospective clinical trial. Arthritis Rheum 2006;54:3310-8.

8. Seror R, Baron G, Hachulla E, Debandt M, Larroche C, Puechal X, et al. Adalimumab for steroid sparing in patients with giant-cell arteritis: results of a multicentre randomised controlled trial. Ann Rheum Dis 2014;73:2074-81.

9. Kermani TA, Kenneth J, Warrington KJ, Cuthbertson D, Carette S, Hoffman GS, et al for the Vasculitis Clinical Research Consortium. Disease relapses among patients with giant cell arteritis: a prospective, longitudinal cohort study. J Rheumatol 2015;42:1213-7.

10. Liozon E, Roblot P, Paire D, Loustaud V, Liozon F, Vidal E, et al. Anticardiolipin antibody levels predict flares and relapses in patients with giant-cell (temporal) arteritis. A longitudinal study of 58 biopsy-proven cases. Rheumatology 2000;39:1089-94.

11. Martínez-Lado L, Calvino-Díaz C, Pineiro A, Dierssen T, Vázquez-Rodríguez TR, Miranda-Filloy JA, et al. Relapses and recurrences in giant cell arteritis: a population-based study of patients with biopsy-proven disease from northwestern Spain. Medicine 2011;90:186-93.

12. Proven A, Gabriel SE, Orces C, O'Fallon WM, Hunder GG. Glucocorticoid therapy in giant cell arteritis: duration and adverse outcomes. Arthritis Rheum 2003;49:703-8.

13. Alba MA, García-Martínez A, Prieto-González S, Tavera-Bahillo I, Corbera-Bellalta M, Planas-Rigol E, et al. Relapses in patients with giant cell arteritis: prevalence, characteristics, and associated clinical findings in a longitudinally followed cohort of 106 patients. Medicine 2014;93:194-201.

14. Aiello PD, Trautmann JC, McPhee TJ, Kunselman AR, Hunder GG. Visual prognosis in giant cell arteritis. Ophthalmology 1993; 100:550-5.

15. Hernández-Rodríguez J, García-Martínez A, Casademont J, Filella $\mathrm{X}$, Esteban MJ, López-Soto A, et al. A strong initial systemic inflammatory response is associated with higher corticosteroid requirements and longer duration of therapy in patients with giant-cell arteritis. Arthritis Rheum 2002;47:29-35.

16. Nesher G, Nesher R, Mates M, Sonnenblick M, Breuer GS. Giant cell arteritis: intensity of the initial systemic inflammatory response and the course of the disease. Clin Exp Rheumatol 2008;26 Suppl 49:S30-4.

17. García-Martínez A, Hernández-Rodríguez J, Arguis P, Paredes P, Segarra M, Lozano E, et al. Development of aortic aneurysm/dilatation during the followup of patients with giant cell arteritis: a cross-sectional screening of fifty-four prospectively followed patients. Arthritis Rheum 2008;59:422-30.

18. García-Martínez A, Arguis P, Prieto-González S, Espígol-Frigolé G, Alba MA, Butjosa M, et al. Prospective long term follow-up of a cohort of patients with giant cell arteritis screened for aortic structural damage (aneurysm or dilatation). Ann Rheum Dis 2014;73:1826-32.

19. Nesher G, Sonnenblick M, Friedlander Y. Analysis of steroid-related complications and mortality in temporal arteritis: a 15-year survey of 43 patients. J Rheumatol 1994;21:1283-6.

J Rheumatol 2015;42:1081-2; doi:10.3899/jrheum.150534

Personal non-commercial use only. The Journal of Rheumatology Copyright $\odot$ (2015. All rights reserved 